\title{
OS DESAFIOS E POSSIBILIDADES DA IGUALDADE DE GÊNERO DENTRO DO CONTEXTO ESCOLAR
}

\author{
Edilson Raniere Gonçalves Pereira ${ }^{1}$ \\ Lady-Anne Pereira Siqueira ${ }^{2}$ \\ Talita Mirella Ferreira da Silva ${ }^{3}$
}

RESUMO: O presente artigo se debruça em torno de uma pesquisa bibliográfica que trata sobre a formação de indivíduos sociais para a construção da igualdade de gênero no contexto social. A revisão bibliográfica traz pontos de importante discussão, colocando a escola como agente responsável pelo trabalho em prol do respeito à diversidade e do combate à qualquer forma de preconceito e discriminação. A abordagem enfatiza diversos grupos sociais que são marginalizados dentro da sociedade e destaca a importância de não somente a escola fazer um trabalho de conscientização, mas também responsabiliza a família e os grupos de amigos assim como demais instituições sociais pelo dever de serem protagonistas neste processo de construção de um ambiente social mais igualitário e livre de qualquer forma de preconceito. Contribuíram com a pesquisa autores como Carvalho ( 2019), Dinis ( 2008), Fronza (2017), Lins e Machado ( 2016), Picirili ( 2019), dentre outros autores que foram essenciais com as discussões postas.

Palavras-chave: Escola. Família. Diversidade. Gênero. Contexto.

ABSTRACT: This article focuses on a bibliographical research that deals with the formation of social individuals for the construction of gender equality in the social context. The literature review brings important points of discussion, placing the school as an agent responsible for working towards respect for diversity and combating any form of prejudice and discrimination. The approach emphasizes several social groups that are marginalized within society and highlights the importance of not only the school carrying out awareness-raising work, but also making the family and groups of friends as well as other social institutions responsible for the duty to be protagonists in this process of construction of a more egalitarian social environment free from any form of prejudice. Authors such as Carvalho (2019), Dinis (2008), Fronza (2017), Lins and Machado (2016), Picirili (2019), among other authors who were essential to the discussions, contributed to the research.

Keywords: School. Family. Diversity. Gender. Context.

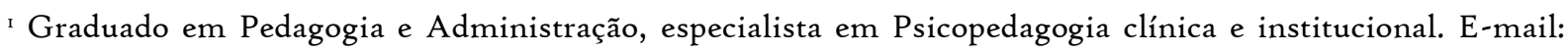
edilsonraniere@gmail.com

${ }^{2}$ Graduada em Psicologia, especialista em gestão de recursos humanos nas organizações, mestranda em Psicologia. E-mail: ladyanne.siqueira@ifsertao-pe.edu.br

3 Graduada em Letras e Direito, especialista em Ensino da Língua Portuguesa. URCA. E-mail: talitamirellaiı@gmail.com
} 


\section{INTRODUÇÃO}

Este artigo traz a discussão em torno da formação dos sujeitos para a construção da igualdade de gênero dentro da sociedade atual, fator que é de responsabilidade de muitas instituições que hoje se encontram imersas no meio social, especialmente a escola com seu papel de construção do pensamento crítico e reflexivo.

Um assunto muito discutido no contexto contemporâneo é a igualdade de gênero, porém é interpretado pela escola como tema que merece pouca discussão e que tem relevância reduzida, dessa mesma forma, é visto pela igreja, pela família e pelas diversas instituições da sociedade. Porém, tratar a igualdade de gênero no espaço da sala de aula ou da escola, assim como nos diversos espaços de educação não formal e informal, propõe um diagnóstico preciso de diversos estereótipos sociais arraigados às diferentes culturas que permeiam o ambiente educativo e que trazem uma carga negativa e repleta de preconceitos.

Neste sentido, o objetivo desta produção é demonstrar os principais aspectos sociais ligados à diversidade em sua generalidade e fazer uma reflexão sobre o contexto da igualdade de gênero nas mais diversificadas instituições da sociedade, em especial a escola. Para que seja alcançado tal objetivo é necessário fazer uma análise dos diversos grupos que se encontram marginalizados, com direitos que foram ou são negligenciados numa sociedade cheia de preconceitos originados, principalmente, pelo seu contexto histórico. Ainda, escolheu-se para a análise a fase da adolescência, uma vez que essa é decisiva para a formação da personalidade assim como para a desconstrução de formas de preconceito e discriminação. É necessário investigar as influências que o adolescente recebe nessa fase de formação da personalidade. Uma etapa da vida que necessita de orientação e acompanhamento escolar, familiar e do relacionamento com seus pares. E, por fim, faz-se necessário abordar como são direcionadas as políticas públicas no país e quais os reflexos disso na educação, além de refletir sobre a influência do contexto escolar formal na garantia do respeito à diversidade e à igualdade de gênero.

Para a elaboração deste trabalho alguns referenciais teóricos se destacam, como Previtalli e Vieira (2017), Lins, Machado e Escoura (2016), Pinto, Ferronato, Freitas (2016), Sousa e Graupe (2014), Constituição Federal de 1988, Lei de Diretrizes e bases da Educação 
Nacional (LDB 9.394/96), que são de essencial importância para sistematização de todo o referencial teórico.

\section{DESENVOLVIMENTO}

\section{IGUALDADE DE GÊNERO E DIVERSIDADE}

Dentro do contexto social, é nítida a multiplicidade de características entre as pessoas, tanto no sentido biológico quanto nos aspectos culturais. Essas diferenças entre pessoas e entre culturas e povos formam o que se conhece como diversidade. A diversidade abrange os diversos contextos sociais, é um instrumento que permite a formação de vários papéis sociais e que deixa aparente a diferença entre um indivíduo e outro.

Quando a diversidade é expressa através de características físicas, é possível percebê-la nas diferenças entre negros e brancos, baixos e altos, gordos e não gordos, menino e menina, heterossexual, bissexual, transexual e homossexual pobres e ricos, escolarizados e não escolarizados, e dentre tantos outros aspectos que classificam as pessoas e as tornam diferentes. Por outro lado, os aspectos culturais também caracterizam grupos e os diferenciam dos demais, por exemplo, o modo como os baianos vivem, as comidas que comem, as músicas que escutam, e dentre outros aspectos, são diferentes quando comparados à cultura pernambucana, ou seja, seus próprios vizinhos. É óbvio que ambas as culturas apresentam similaridades, porém, mesmo com estas, cada uma apresenta sua particularidade e isso caracteriza o termo diversidade.

Dentre tantas diferenças existentes no meio social, é importante destacar que grande parte dessa diversidade é produzida pelos próprios indivíduos como sujeitos sociais, através das suas culturas que são transmitidas de geração em geração.

\footnotetext{
Segundo Durkheim (20or), a sociedade exerce uma força que impõe a cada indivíduo o que deve ser assimilado para depois ser transmitido para as novas gerações. Assim, com a assimilação das normas e dos valores, a criança é socializada para que possa conviver em sociedade. Sendo assim, se a educação serve para a socialização das pessoas, concluímos que cada grupo social teria uma educação específica, pois ela reflete o papel social que cada indivíduo deve representar naquela sociedade. (DURKHEIN apud PREVITALLI E VIEIRA, 2017, p.13)
} 
A sociedade como principal instituição em que o indivíduo está em constante interação é a responsável por construir os aspectos culturais no indivíduo, direcionando a forma como deve agir e se comportar e quais princípios que deve seguir.

As relações entre as pessoas constroem no indivíduo uma carga muito grande de crenças, o que fornece subsídios para a formação da sua personalidade. Porém, em toda a história, o fato de existir inúmeras culturas e diversos modos de pensar e agir gerou diversos conflitos, tanto físicos como de opinião.

A diversidade nunca foi vista como algo pacífico durante toda a história da humanidade e até hoje, as diferenças causam atrito entre os indivíduos em sociedade. Mesmo com o desenfreado processo de industrialização e avanço tecnológico, é notável que durante toda a história a não aceitação da cultura ou da forma física ou ainda das opções do outro causam dilemas sociais com repercussões bastante negativas, o que gera o chamamos de preconceito.

[...] entendemos que o preconceito é um atributo pejorativo que estigmatiza 1834 alguém e também desumaniza tanto quem é preconceituoso, quanto quem sofreu o preconceito. Por ser assim, o preconceito é construído na relação com o outro, pois enquanto normatiza ou padroniza um, estigmatiza o outro.(PREVITALLI E VIEIRA, 2017, p.29)

A criação de estereótipos, como o de que a mulher deve ser preparada para os afazeres domésticos resultou numa espécie de mutilação do sexo feminino, em que durante séculos da história não pôde exercer papéis sociais na política, no mercado de trabalho e em diversos outros setores sociais.

Segundo Lins, Machado e Escoura (2016), frases do tipo "menino não chora" ou "toda mulher quer ser mãe" cria estereótipos sociais que se relacionam a um determinado indivíduo que no caso é o sexo masculino ou feminino.

De certa forma, esses padrões ou aspectos criados pela sociedade para identificar homens e mulheres serviram e ainda servem até hoje para justificar as inúmeras injustiças e desigualdades sociais, como o fato da mulher entrar no mercado de trabalho de forma tardia e os baixos salários recebidos por estas em comparação aos recebidos pelo sexo oposto. Até os dias atuais, a mulher, mesmo trabalhando, precisa assumir as tarefas da casa numa situação em que homem e mulher trabalham fora de casa. É claro observar que este 
contexto tem mudado em relação a décadas passadas, mas num processo muito lento e ainda pouco disseminado na sociedade contemporânea.

Segundo Dinis (2008), o debate, no Brasil, sobre diversidade de gênero ocorre desde I970 por pressão, principalmente, de grupos feministas, dessa forma, verifica-se que é ainda recente, considerando a longa existência da sociedade civil.

Preconceitos relacionados ao sexo feminino não impactaram apenas as mulheres, mas também trouxeram consequências para os próprios homens. É possível citar como exemplo as inúmeras profissões deixadas de serem exercidas pelo sexo masculino ou serem vistas como algo relacionado às mulheres, neste sentido, é possível destacar profissões como o balé e também como destaca Lins, Machado e Escoura (2016) a de professor, principalmente do $\mathrm{I}^{\mathrm{o}}$ ao $5^{\mathrm{o}}$ ano do ensino fundamental, o que ocasionou uma desvalorização salarial que perdura até os dias atuais.

Porém, as diferenças que provocam o fenômeno da diversidade, não se restringem apenas a estabelecer separações entre sexo masculino e feminino, mais perpassa os diversos sujeitos sociais estabelecendo relações demasiadamente desiguais. O preconceito racial foi e ainda é um dos grandes mártires sociais que negligencia abertamente os direitos do indivíduo viver com igualdade, equidade e justiça. Nesta direção, Previtalli e Vieira (2017) revelam que, no Brasil, os negros foram marginalizados de tal forma que ainda hoje buscam ascensão social. Ainda, para Fronza (2017) o racismo cria estereótipos considerados negativos e que afetam crianças e jovens negros, o que, obviamente, cria espaço para desigualdades.

Durante séculos da história, com destaque para o Brasil, as pessoas negras foram vítimas da escravidão, o que ocasionou problemas sociais que se estendem até hoje. Particularmente no cenário nacional, é possível perceber que a escravidão trouxe para o Brasil contemporâneo uma grande população pobre e negra que, sem equidade de condições, se refugiou e criou as grandes favelas que hoje são centros de pobreza e marginalização, além de que os estereótipos criados em torno da população negra perduram até hoje, gerando, a todo instante, formas de preconceito e injúria racial, a desigualdade de condições de estudo, trabalho e inclusão social.

Sobre racismo, Fronza (2017, p.7) relata, 
As ideias preconceituosas acerca das diferenças raciais tiveram forte influência em vários períodos vivenciados pela sociedade no decorrer da história humana em que foram vivenciados crimes terríveis contra a dignidade da pessoa humana. E o racimo foi um desses crimes praticados pela sociedade.

Não bastasse as inúmeros formas de discriminação e injustiça entre homens e mulheres e diferenças entre raças e cor da pele, é possível identificar o preconceito massivo em torno da condição sexual de muitas pessoas. A comunidade LGBT-Lésbicas, Gays, Bissexuais e Trangênero- há muito sofre com as mazelas provocadas por uma sociedade altamente preconceituosa e segregacionista. Desde o tratamento em público e em redes sociais até a oportunidade de inserção no mercado de trabalho, a comunidade LGBT têm sofrido na sociedade atual por não se enquadrar nos padrões criados pela sociedade durante toda a história, principalmente pela igreja. Não é estranho presenciar noticiários e depoimentos relacionados a preconceitos e agressões contra homossexuais, casos como o de $\mathrm{X}$ publicado no site $\mathrm{O}$ Globo em maio de 2019, em que após assumir sua sexualidade foi exposta as mais diversas frustrações e exposições na igreja a qual seus pais frequentavam, no intuito de conseguir a utópica "cura gay". Casos como os retratados na teledramaturgia refletem a realidade vivida pelo público homossexual, realidade esta permeada pela violência que acontece diariamente.

Às vezes o preconceito contra o grupo LGBT vem oculto, a exemplo do que postula Dinis (2008) quando revela que qualquer brasileiro tem em sua memória uma autoridade que defende os direitos dos negros, das mulheres, dos presidiários, mas quando o assunto é o combate à homofobia, simplesmente, silencia-se.

A intolerância e os preconceitos contra as diferenças não se limitam apenas aos grupos citados, mas refletem nos vários contextos e indivíduos sociais, como contra os portadores de deficiência, contra as diversas culturas, contra indígenas, contra diferenças regionais, contra nações e regiões e até mesmo contra religiões e dentre muitos aspectos e setores do ambiente social.

\section{A IMPORTÂNCIA DA ESCOLA, DA FAMÍlIA E DOS GRUPOS DE AMIGOS DURANTE A ADOLESCÊNCIA}

Percebendo que a sociedade é um todo integrado e que a diversidade é algo que está presente nos vários ambientes sociais, é possível verificar claramente que esta repercute no ambiente escolar, nesse sentido é necessário o trabalho em sala de aula com crianças, 
jovens e adultos na direção da valorização e do respeito às diferenças e à diversidade. Nessa perspectiva, é imprescindível a importância da atuação da escola na promoção de sujeitos sociais desmistificados e livres de preconceitos e estereótipos criados pela sociedade em torno da diversidade.

Segundo Silva e Luz (2010) a escola é o primeiro lugar público que as crianças frequentam, tendo assim a oportunidade de vivenciar experiências novas que se diferenciam daquelas vivenciadas no seio familiar. Isso sinaliza para a atuação da escola, desde cedo, na conscientização do respeito à diversidade.

Outra instituição que também é de fundamental importância é a família, que tem um papel imprescindível na formação do sujeito, é a primeira instituição a qual o indivíduo se situa, além de dividir com a escola, segundo Previtalli e Viera (2017), a responsabilidade pelo desenvolvimento educacional.

Diante dessa abordagem entre escola e família, é importante destacar a atuação destas instituições na formação do sujeito social, principalmente quando se fala no respeito à diversidade e às diferenças. Pensando nisso, é importante destacar uma das fases do desenvolvimento humano que se caracteriza por uma série de transformações no indivíduo e é crucial para o desenvolvimento de sua personalidade: a adolescência.

A adolescência é o período do desenvolvimento compreendido entre os I2 e os 18 anos, geralmente. De modo geral, pode ser entendida como o período de transição para a idade adulta. É um período marcado por mudanças bem delimitadas, mas também permeado por questões culturais e sociais bastante típicas. (PINTO, FERRONATO, FREITAS, 2016, p. 127).

Pela definição da fase da adolescência é possível perceber que é um período de grandes mudanças, um verdadeiro “divisor de águas”. Diante disso, é consciente dizer que a escola é uma instituição de grande influência e de orientação nessa fase de desenvolvimento.

A escola deve estar preparada para receber os educandos que se encontram nesta faixa etária (12 a I8 anos), promovendo as mais diversas formas de orientação e promoção do respeito à diversidade.

Percebemos, portanto, o quanto os adolescentes clamam por espaços de colocação, o quanto necessitam que seus olhares, suas vivências, seus pensamentos reflexivos e seus desejos sejam incluídos na construção do modelo educacional. Mas para isso, é preciso que as escolas se sustentem enquanto lugar de formação 
de sujeitos-cidadãos para que crianças e adolescentes possam ser porta-vozes de si mesmos. (PICIRILLI, 2019, p.29)

A adolescência é a fase em que acontece o despertar para a sexualidade, nesse sentido, a escola, como agente social da educação, necessita discutir essa realidade com os adolescentes, permitindo que estes se sintam à vontade para expressar suas vontades e que possam compreender seus anseios para que tenham consciência de seus próprios atos e necessidades. Precisa envolver os adolescentes no meio educativo através de estratégias metodológicas que permitam ao adolescente uma formação orientada para a quebra de paradigmas e de concepções negativas criadas ao longo da história pela sociedade.

É necessário que a instituição escolar transforme o modo como a sociedade empregou determinados estereótipos, de modo a desmistificar o que cita Lins, Machado e Escoura (2016) quando revelam que as diferenças entre o corpo feminino e masculino foram transformadas em desigualdades, consideradas naturais ao longo da história, através de um processo histórico e cultural que criou estereótipos. Os adolescentes precisam ver na escola que essas desigualdades geram preconceito, discriminação, desvalorização e segregação entre ambos os sexos. Mas não é somente quanto à igualdade de gênero que os adolescentes devem ser educados, mas também no sentido de respeito às diversas culturas e modos de viver, músicas, rituais, orientação sexual, religião e diversos outros aspectos que se encontram no meio social.

A família, por sua vez, é uma instituição de grande influência na formação do indivíduo, é a primeira forma de contato social da criança, onde ela vai formar seus primeiros princípios e valores que são carregados por toda a vida. Nesse sentido, a família tem grande influência na fase da adolescência do indivíduo, principalmente por ser uma fase de grandes mudanças, necessita de uma ação ainda mais intensa desta instituição social. Porém, muitas vezes a família contribui para a formação de uma identidade diversa daquela almejada pelo contexto e, às vezes, chegam a reprimir o adolescente de diversas formas, a exemplo do que Picirilli (2019) traz quando denuncia que determinados tipos de familiares reprimem toda manifestação de diversidade, especialmente no que diz respeito à sexualidade.

A instituição familiar precisa conhecer o adolescente na sua integralidade, não como um indivíduo que é rebelde e que quebra regras - mito repassado de geração em 
geração - mas como sujeito que se encontra em processo de desenvolvimento e de busca da personalidade. Nesse sentido, cabe à família orientar o adolescente no sentido de tomar decisões e fazer escolhas que proporcionam a sua autossatisfação e também promovam sua inserção atuante dentro do meio social. Através de uma boa orientação e de um núcleo familiar livre de preconceitos e discriminações, o adolescente se sente mais seguro para tomar decisões, fazer suas escolhas de modo consciente, com mais possibilidades de sucesso.

A escola e a família precisam estar interligadas nesse processo de desenvolvimento do adolescente, impedindo que uma desconstrua aquilo que a outra construiu no jovem. Esta parceria solidifica e traz segurança para o adolescente, principalmente se esta relação for permeada por princípios e atitudes de respeito à diversidade.

Família e escola precisam, juntas, criar uma força de trabalho para superarem as suas dificuldades, construindo uma identidade própria e coletiva; para isto, é fundamental que se encarem como parceiras de caminhada, pois ambas as duas são responsáveis pelo que produzem - podendo reforçar ou contrariar a influência uma da outra. (SOUZA E FILHO, 2008, p. 7)

Além da família e da escola, os adolescentes mantêm uma relação próxima com seus pares. Nessa fase, são comuns os grupos de amigos e o aparecimento de casais, estes grupos se caracterizam por serem mistos, não apenas grupos de meninos ou grupos de meninas. Esse cenário é bastante comum na adolescência, mas tende a ser difundido nele estereótipos tanto da família como da própria escola como, por exemplo, o fato de dizer que "meninos andam com meninos e meninas andam com meninas", circunstância que descaracteriza os grupos de amigos e põe em risco a oportunidade dos adolescentes viverem a adversidade.

Os grupos de amigos são uma necessidade dos adolescentes e isso pode ter aspectos positivos e negativos na vida do indivíduo. O fato de estar próximo de seus pares transmite segurança e compartilhamento de ideias, perspectivas, e são estabelecidos diversos vínculos que colaboram com a formação da sua personalidade e autonomia. A convivência no grupo, muitas vezes, quebra muitos preconceitos vindos, até mesmo, da própria família do adolescente. Para Picirilli (2019) quando o indivíduo se sente pertencente a algum grupo de jovens, ele começa a criar uma consciência de classe que 
problematiza historicamente suas vivências. Daí a importância do contato constante com seus pares.

Atualmente, por exemplo, é nítido perceber como os adolescentes tratam com mais naturalidade a questão do homossexualismo que há io ou 20 anos. Essa quebra de paradigma entre os jovens se dá principalmente pela convivência entre os pares, o que prova o fato do preconceito ser algo construído historicamente pela sociedade e que pode ser potencializado ou enfraquecido por ela, a depender das ações realizadas pelos seus indivíduos.

As noções de gênero, sexualidade e educação são entendidas como construtos sociais que se fundamentam por meio da historicidade e do caráter provisório das culturas. Classificar alguém como masculino ou feminino, homossexual, heterossexual ou bissexual está intimamente ligado ao que o gênero e a sexualidade produzem como saberes e verdades na sociedade. (PREVITALLI E VIEIRA, 2017, p.I64)

Por outro lado, a convivência com o grupo de amigos pode influenciar negativamente o adolescente quando este não é bem aceito. Seja por aspectos físicos ou sociais, o adolescente se retrai, tem dificuldade de relacionamento e de não ser aceito, principalmente em sua aparência física e isso pode gerar baixa autoestima e consequentemente levar à depressão, uma doença psicológica que se encontra no auge pela quantidade de casos diagnosticados, principalmente em adolescentes.

As relações das redes sociais entre os pares também podem contribuir positivamente ou negativamente. A busca de likes de amigos, muitas vezes não atendida, frustra as expectativas e gera ansiedade nos adolescentes.

A influência de adolescentes que foram criados e educados em ambiente familiar cheio de dogmas e crenças preconceituosas faz com que esses princípios retrógrados sejam repassados nos grupos de amigos.

\section{POLÍtICAS PÚBLICAS E IGUALDADE DE GÊNERO ATRELADA À EDUCAÇÃO}

Quando se fala em políticas públicas muitas vezes se tem a ideia de que estas são remédios sociais utilizados para amenizar determinado problema existente na sociedade. Porém, as políticas sociais assim entendidas as públicas, tem um conceito e abrangência bem maior, pois são estratégias que fornecem à sociedade igualdade, justiça e 
principalmente equidade. Dentre tantos tipos de políticas públicas existentes, é possível destacar aquelas ligadas à igualdade de gênero no Brasil, que são recentes e mostram o quanto o país age de maneira tardia quanto a esse tema.

Segundo Sousa e Graupe (2014), as conquistas das mulheres estão atreladas a movimentos feitos por estas durante toda a história, que comprova o quanto o contexto histórico e social foi desigual entre os sexos.

Com a redemocratização do país na década de 80, inúmeras conquistas foram alcançadas no sentido de igualdade de gênero. Através da constituição federal de 1988 que, em diversos dispositivos, garante a igualdade entre homens e mulheres e também em diversas legislações paralelas como a Lei de Diretrizes e Bases da Educação Nacional (LDB- 9.394/96), que no seu artigo $3^{\circ}$ garante a igualdade de condições para acesso e permanência na escola e o respeito à liberdade e apreço à tolerância. Essas legislações são também formas de políticas públicas que garantem a igualdade de tratamento entre os gêneros, apesar de que, na realidade, o contexto real é, muitas vezes, diverso daquele desenhado na legislação.

Outro caso de luta pela igualdade de tratamento é o caso de Maria da Penha Maia, que foi agredida pelo marido durante seis anos até se tornar paraplégica. Em homenagem a Maria da Penha, foi criada a lei que leva o seu nome e que tornam mais rigorosas as penas por agressões contra a mulher- outra política que, de certa forma, tem como intuito extinguir o estereótipo de subordinação da mulher criado pelo contexto histórico.

Ainda, falando da constituição federal de 1988, é importante destacar o texto do artigo $3^{\circ}$, inciso IV, que revela um dos objetivos fundamentais da República Federativa do Brasil: "promover o bem de todos sem preconceitos de origem, raça, sexo, idade e quaisquer outras formas de discriminação”. Nesse inciso, é possível verificar que, aos inúmeros grupos sociais, é garantido o desenvolvimento sem nenhum tipo de discriminação. Nesse dispositivo está visivelmente claro que a igualdade de gêneros é promovida e é uma garantia que deriva de muitas lutas antecedentes à constituição, travadas principalmente durante o período militar.

Diante desse cenário, é necessário destacar que a legislação apenas no papel de nada vale, é preciso que seja efetivamente materializada no contexto social. Para que isso aconteça, faz-se necessário que as diversas instituições sociais promovam e potencializem a 
concretização dessas políticas e legislações frutos da democracia. A escola como principal sujeito social responsável pela construção de saberes é parte fundamental nesse processo.

A escola precisa potencializar a diversidade de gênero, trabalhar as individualidades e particularidades de cada um, não no sentido de um se sobressair sobre o outro, mas demonstrando a importância de ambos para a integralidade social, a contribuição de cada um e os papéis que cada um tem dentro do constructo social. Nesse sentido, Dinis (2008) expõe que para construir um novo exercício pedagógico é necessário reinventar as relações, liberar a vida aprisionada, tornar-se outra coisa.

O projeto político pedagógico e a proposta pedagógica da instituição escolar necessitam propor estratégias e ações que viabilizem a igualdade de gênero, não apenas dentro do ambiente escolar, mas nos diversos espaços onde é necessária a relação de respeito e o combate ao preconceito e às formas de discriminação de gênero. Os projetos interdisciplinares e transversais $e$ as parcerias com instituições extraescolares proporcionam a viabilidade do trabalho direcionado à igualdade de gênero. A família junto com a escola também, dependendo da relação que é estabelecida, garantem a formação de indivíduos mais comprometidos com a igualdade de gênero e respeito à diversidade.

\section{CONSIDERAÇÕES FINAIS}

Diante das discussões, é notório perceber que o tema igualdade de gênero é algo emergente na sociedade contemporânea, que precisa ser debatido pelas diversas instituições no intuito de construir com as novas gerações um senso crítico livre de qualquer tipo de preconceito.

Através do contexto apresentado inicialmente, em que se relacionou as diversas formas de segregação de grupos sociais, foi possível concluir que é urgente a quebra de estereótipos tanto os presentes na ideologia dos professores quanto na dos alunos, para que seja promovida uma verdadeira igualdade e respeito à diversidade dentro do espaço escolar.

Evidenciamos aqui diversas formas de discriminação que são originárias do contexto social e têm como intuito a inferiorizarão de um grupo em relação a outro. Essas evidências revelam que é necessário um trabalho constante e articulado, não somente da escola, como citado anteriormente, mas de toda a sociedade civil, para, assim, romper com qualquer tipo de desigualdade. 
Ao analisar os papéis da família, da escola e dos grupos de amigos na formação do adolescente, constatou-se o quanto essas instituições têm influência na formação da personalidade do adolescente, nas escolhas destes e principalmente na promoção da igualdade de gênero. Por fim, conclui-se que as políticas públicas, legislações, sociedade e espaço escolar podem e precisam nortear caminhos positivos rumo à igualdade de gênero.

\section{REFERÊNCIAS}

BRASIL. Constituição da República Federativa do Brasil. Brasília: Senado Federal, Coordenação de edições técnicas, 2016.119 p.

BRASIL. LDB : Lei de diretrizes e bases da educação nacional. Brasília: Senado Federal, Coordenação de Edições Técnicas, 2017.58 p.

CARVALHO, Victor. Experiências com “cura gay” revelam histórias de dor e sofrimento na comunidade LGBT+. O Globo, 26 de abril de 2019. Disponível em < https://oglobo.globo.com/celina/experiencias-com-cura-gay-revelam-historias-de-dorsofrimento-da-comunidade-lgbt-23622628 > Acesso em or de dez. 2021.

DINIS, Nilson Fernandes. Educação, relações de gêneros e diversidade sexual. Educ. Soc., Campinas, vol. 29, n. I03, p. 477-492, maio/ago. 2008. Disponível em < https://www.scielo.br/j/es/a/nTn98Ch9xWZdqbcSFwXkykw/?lang=pt\&format=pdf $>$ Acesso em 03 de dez. 2021

FRONZA, Maíra. Ações afirmativas como medidas para o estabelecimento da igualdade de raças. Derecho y Cambio Social, ISSN: 2224-4131. Depósito legal: 2005-5822, 2017. Disponível em < https://www.derechoycambiosocial.com/revista 048/AS_ACOES_AFIRMATIVAS_COMO_MEDIDAS.pdf $>$ Acesso em o3 de dez. 202I. LINS, Beatriz Accioly; MACHADO, Bernando Fonseca; ESCOURA, Michele. Entre o azul e o cor-de-rosa: normas de gênero. In. (Orgs.). Diferentes, não desiguais: a questão de gênero na escola. São Paulo: Editora Reviravolta, 2016.

PICIRILI, Claúdia Capelini. Adolescência e juventude no século XXI. Londrina : Editora e Distribuidora Educacional S.A., 2019. 
PINTO, Rosângela de Oliveira; FERRONATO, Raquel Franco; FREITAS, Márcia de Fátima Rabelo Lovisi. Psicologia da educação e aprendizagem. Londrina: Editora e Distribuidora Educacional S.A., 2016.

PREVITALLE, Ivete Miranda; VIEIRA, Hamilton E. Santos. Educação e diversidade. Londrina: Editora e Distribuidora Educacional S.A., 2017.

SILVA, Isabel de Oliveira de; LUZ, Isa Rodrigues da. Meninos na educação infantil: o olhar das educadoras sobre a diversidade de gênero. Cadernos pagu (34), janeiro-junho de 2010:17-39. Disponível em < https://www.scielo.br/j/cpa/a/HWLCtRczHV

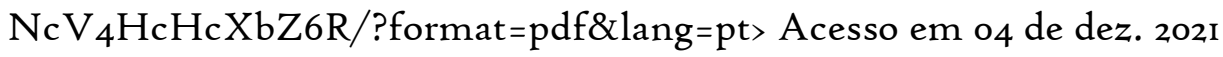

SOUZA, Ana Paula de; FILHO, Mário José. A importância da parceria entre família e escola no desenvolvimento educacional. Revista Iberoamericana de Educación ISSN: I68I5653 n. $.94 / 7$ - io de enero de 2008 SOUZA, Lúcia Aulete Búrigo; GRAUPE, Mareli Eliane. Gênero e Políticas Públicas na

Educação. In. Anais do III Simpósio Gênero e Políticas Públicas, Universidade Estadual de Londrina, 27 e 29 de maio de 2014. 